\title{
MODELING SWASH ZONE SEDIMENT TRANSPORT AT TRUC VERT BEACH
}

\author{
Arnold van Rooijen ${ }^{1,2}$, Ad Reniers ${ }^{3}$, Jaap van Thiel de Vries ${ }^{1,2}$, Chris Blenkinsopp ${ }^{4}$, and \\ Robert McCall ${ }^{1,5}$
}

\begin{abstract}
A one-dimensional hydrostatic version of the XBeach model (Roelvink et al., 2009) is applied to hindcast swash morphodynamics measured during an accretive, and an erosive tide at Le Truc Vert beach (France) in early spring 2008 (Masselink et. al, 2009; Blenkinsopp et al., 2011). Swash hydrodynamics are solved by applying the nonlinear shallow water equations, and sediment transport rates are obtained from a combined intra-wave Nielsen and Bagnold type transport model. Reasonable predictions of morphological change in the swash were obtained. Nevertheless, the model underpredicts the water level setup and/or wave run-up during the accretive tide, which is hypothesized to be related to $2 \mathrm{D}$-effects.
\end{abstract}

Keywords: numerical modeling, swash zone, sediment transport, XBeach, bed load, suspended load, le Truc Vert

\section{INTRODUCTION}

The swash zone is a dynamic area, characterized by strong and unsteady flows, high turbulence levels, large sediment transport rates and relatively large morphological changes in a small timescale. These complex physical processes, in combination with the difficulty to conduct measurements in the swash zone (for instance due to the very low water depths), have led to a relatively poor understanding of the swash at present. This makes numerical modeling of sediment transport in the swash zone challenging (Bakhtyar et al., 2009). Good knowledge of the swash is, however, important for several purposes, for instance beach stability assessment and design of beach nourishments (e.g. interaction of wave and tide driven sediment transport with aeolian transport).

In the last decades researchers have developed numerous process-based numerical models, which are used as a tool to predict sediment transport rates and morphological changes, and to obtain insight into the morphodynamic processes taking place on a sandy coast. Comparisons of model predictions with field or lab data generally show that models are reasonably able to represent the observed processes along most parts of the coastal profile well (for instance the surf zone), but that the sediment transport rates and morphological changes in the swash zone are often overestimated, especially during mild wave conditions. In the current study a process-based numerical model is used to predict morphological changes specifically in the swash zone. The objective is to be able to predict both accretion and erosion on a small time (intra-wave) and spatial $(\mathrm{O}(\mathrm{cm}))$ scale.

This paper is organized as follows: first, the modeling approach is described, followed by an overview of the model formulations. Then a description of the case study is provided, and the model results are discussed. Finally, some conclusions of the study are presented.

\section{MODELING APPROACH}

The (depth-averaged) XBeach model (Roelvink et al., 2009) was originally designed to simulate storm impact on dunes and barrier islands. It combines a wave action balance with the nonlinear shallow water equations (NSWE) to solve high and low frequency wave motions, respectively. This modeling concept is known as the surf beat approach.

In the present study the offshore model boundary is located in very shallow water. The maximum water depth observed at this location is approximately 1 to $1.5 \mathrm{~m}$, and most of the wave energy was found to be associated with $k h$-values smaller than 0.5 . Therefore, all wave motions are considered shallow water waves here, which can be solved for using solely the nonlinear shallow water equations.

${ }^{1}$ Deltares, Rotterdamseweg 185, 2629 HD, Delft, The Netherlands

${ }^{2}$ Faculty of Civil Engineering and Geosciences, dep. of Hydraulic Engineering, Delft University of Technology, Stevinweg 1, 2628 CN, Delft, The Netherlands

${ }^{3}$ Rosenstiel School of Marine and Atmospheric Sciences, University of Miami, 4600 Rickenbacker Causeway, Miami, FL 33149, U.S.A.

${ }^{4}$ School of Civil and Environmental Engineering, University of New South Wales, Sydney, NSW 2052, Australia

${ }^{5}$ School of Marine Science and Engineering, University of Plymouth, Drake Circus, Plymouth, PL4 8AA, United Kingdom 
An advantage of using the nonlinear shallow water equations with respect to the surf beat approach is that hydrodynamic results can be compared directly with the total measured (instantaneous) water level and velocity signals, since all wave motions are fully resolved.

Two sediment transport formulas are presently implemented in XBeach; Soulsby-van Rijn (1997) and Van Rijn (2007), which were originally developed to predict transport rates based on flow statistics (i.e mean flow velocity and root mean square flow velocity). Here, a newly implemented combined Nielsen and Bagnold type sediment transport model, described in Reniers et al. (submitted), is used to compute intra-wave sediment transports.

In this study the capability of the model for simulating swash morphodynamics is verified using a field (swash) dataset, and is assessed by comparing measured and modeled water level/bed level and velocity time series (in the swash zone), and by comparing the measured and modeled bed changes along the cross-shore profile during a tidal event.

\section{MODEL DESCRIPTION}

\section{Hydrodynamics}

In the present study a one-dimensional hydrostatic version of the XBeach model (Roelvink et al., 2009) is used to resolve the swash zone hydrodynamics and sediment transport. It is assumed that the fluid motion in the swash zone can be considered dominantly shore normal, thereby, allowing a 1D modeling approach. The one-dimensional NSWE are given by:

$$
\begin{aligned}
\frac{\partial u}{\partial t}+u \frac{\partial u}{\partial x}-v_{h}\left(\frac{\partial^{2} u}{\partial x^{2}}\right) & =-\frac{\tau_{b x}}{\rho h}-g \frac{\partial \eta}{\partial x} \\
\frac{\partial \eta}{\partial t}+\frac{\partial h u}{\partial x} & =0
\end{aligned}
$$

where $u$ is the flow velocity in $\mathrm{x}$-direction (positive onshore), $v_{h}$ is the horizontal turbulent eddy viscosity, $\tau_{b x}$ is the bed shear stress, $\rho$ is the water density, $h$ is the local water depth, $\eta$ is the free water surface elevation, and $g$ is the gravitational acceleration. The bed shear stress is computed as a function of the instantaneous free stream velocity and a friction factor $\left(c_{f}=g C^{-2}\right.$, where $C$ is the Chézy coefficient):

$$
\tau_{b x}=\rho c_{f}|u| u
$$

The smallest (turbulent) fluid motions cannot be modeled by the NSWE, and are therefore taken into account separately. This is done by means of a turbulence balance, which is described in Reniers et al. (submitted), where the turbulent intensity is a function of the local water level gradient and a userdefined critical wave slope. When the water level gradient exceeds the critical wave slope, the wave will start breaking and turbulence is created. Next, the turbulence at the water surface is translated into a turbulent intensity at the bed with an exponential decay function. In the swash this will generally lead to higher sediment concentrations in the uprush (or run-up) phase, leading to larger onshore sediment transports.

\section{Bed load transport}

For bed load transport the sediment transport formulation of Nielsen $(1992,2002)$ is used, which is adapted from the shear stress based bed load transport model by Meyer-Peter \& Müller (1948):

$$
q_{b}=12\left[\max \left(\left|\theta^{\prime}(t)\right|-\theta_{c r}, 0\right)\right] u_{*}(t) D_{50}
$$

where $\theta_{c r}$ is the Shields criterion for initiation of motion of sediment (usually equal to 0.05 ), $u *$ is the shear velocity, $D_{50}$ is the median grain diameter, and $\theta^{\prime}$ is the Shields parameter (Shields, 1936) with an additional term for the wave breaking induced near bed turbulence $\left(k_{b}\right)$ :

$$
\theta^{\prime}=\frac{u_{*}^{2}+k_{b}}{g \Delta D_{50}}
$$

To account for boundary layer effects Nielsen (1992) introduced a phase shift $\left(\varphi_{t}\right)$ to calculate the shear velocity as a function of the free stream velocity. The inclusion of a phase shift leads to higher shear stresses under accelerating flow (Nielsen, 2002), thereby increasing the swash cycle asymmetry (difference between uprush and backwash sediment transport). The shear velocity is given by: 


$$
u_{*}=\sqrt{0.5 f_{2.5}}\left(\cos \left(\varphi_{t}\right) u+\sin \left(\varphi_{t}\right) \frac{1}{\omega_{p}} \frac{\partial u}{\partial t}\right)
$$

where $\omega_{p}$ is the peak angular frequency, and $f_{2.5}$ is a wave friction factor corresponding to a bed roughness of $2.5 D_{50}$, given by Swart (1974):

$$
f_{2.5}=\exp \left(5.5\left(\frac{2.5 D_{50}}{S}\right)^{0.2}-6.3\right)
$$

where $\mathrm{S}$ is the swash excursion length, here computed as a function of the offshore wave height and wave length according to Stockdon et al. (2006). The fluid acceleration term in equation (6) is calculated as the difference between the current velocity and the velocity in the former time step divided by the local time step, where for numerical stability a running average is applied:

$$
\frac{\partial u(t)}{\partial t}=\frac{1}{T_{a}} \int_{t-T a}^{t} \frac{u(t)-u(t-\partial t)}{\partial t} d t
$$

where $T_{a}$ is the time period over which the running average is applied and $\partial t$ is the numerical time step. Finally, the effect of a sloping bed is accounted for with an expression by Fredsøe \& Deigaard (1992):

$$
\theta_{\beta}=\theta_{\beta=0} \cos \beta\left(1-\operatorname{sign}(u(t)) \frac{\tan \beta}{\tan \phi}\right)
$$

where $\beta$ is the local bed slope and $\phi$ is the friction angle of the sediment, thereby enhancing down-slope transport, while inhibiting up-slope sediment transport.

\section{Suspended load transport}

The suspended sediment transport is computed using a depth-averaged advection diffusion equation (Galapatti \& Vreugdenhil, 1985):

$$
\frac{\partial h c}{\partial t}+\frac{\partial h c u}{\partial x}+\frac{\partial}{\partial x}\left(D_{s} h \frac{\partial c}{\partial x}\right)=\frac{h\left(c_{e q}-c\right)}{T_{s}}
$$

where $c$ is the depth-averaged sediment concentration, $D_{s}$ is a sediment diffusion coefficient, $c_{e q}$ is the equilibrium sediment concentration, and $T_{s}$ is the adaptation time, given by:

$$
T_{s}=\max \left(0.05 \frac{h}{w_{s}}, 0.2\right)
$$

where $w_{s}$ is the fall velocity of the sediment particles given by Ahrens (2000). The sediment transport is represented by the equilibrium sediment concentration $\left(c_{e q}\right)$, which is rewritten from the Bagnold-type formulation by Roelvink \& Stive (1989):

$$
c_{e q}=\frac{\varepsilon_{s}}{g w_{s} h \Delta n_{p}}\left(\beta_{d} k_{b}^{3 / 2}+c_{f}|u(t)|^{3}\right)
$$

\begin{tabular}{|c|c|c|c|c|c|c|}
\hline $\begin{array}{l}C \\
55\end{array}$ & $\begin{array}{l}\beta_{d} \\
0.01\end{array}$ & $\begin{array}{l}\varepsilon_{s} \\
0.01\end{array}$ & $\begin{array}{l}\varphi_{t} \\
28\end{array}$ & $\begin{array}{l}T_{a} \\
0.5\end{array}$ & $\begin{array}{l}\theta_{c r} \\
0.05\end{array}$ & $\begin{array}{l}\tan (\phi) \\
0.3\end{array}$ \\
\hline
\end{tabular}

where $\varepsilon_{s}$ is an efficiency parameter (which is 0.01 according to Bagnold (1966)), $n_{p}$ is the sediment porosity, and $\beta_{d}$ is a calibration factor associated with the stirring of sediment by the near-bed turbulence $\left(k_{b}\right)$. The relevant model parameters, including the corresponding values used in this study, are given in Table 1. 


\section{MODEL APPLICATION}

\section{Case description}

The dataset used in this study is obtained at the beach of Le Truc Vert, France, during the early spring of 2008 (Masselink et al., 2009; Blenkinsopp et al., 2011). The experiment specifically aimed to obtain detailed swash measurements on a small time and spatial scale. The measurements in the swash zone were made using an array of non-intrusive acoustic bed level sensors mounted at $1 \mathrm{~m}$ cross-shore intervals on a scaffold rig. The bed level sensors were directed downward and measured either the water level (when there was a swash event) or the bed level (when the bed was dry). This measurement technique resulted in combined water level/bed level time series, that can be compared directly with the model output.

Further offshore (at approximately 1 to $1.5 \mathrm{~m}$ water depth during high tide) a pressure transducer (PT) and an acoustic Doppler velocimeter (ADV) were installed to obtain water level and velocity time series. The total beach profile was measured during every low tide using a total station. Eleven crossshore transects, with a spacing of $20 \mathrm{~m}$, were measured from approximately mean low tide level until the crest of the foredune, and were averaged in alongshore dimension to obtain a representative cross-shore profile (see Figure 1). More information on these measurements can be found in Masselink et al. (2009) and Blenkinsopp et al. (2011).

The model hindcast period includes one accretive (high tide 5, or HT 5) and one erosive tide (high tide 6, or HT 6), which are described in Blenkinsopp et al (2011). For HT 5 a period of approximately 3 hours is modeled (March 20th 2008, 01:25-4:40PM), whereas for HT 6 a period of nearly 6 hours is simulated (March 21st, 00:30-06:15AM). The simulation time is based on the duration of the water level reaching at least the offshore located PT and ADV $(x=-79.5 \mathrm{~m}$, see Figure 1), which only occurs during high tide. During HT 6 the waves were considerably larger (Table 2), which likely resulted in a larger wave run-up and set-up. This is the reason why swash events were measured over a longer period of time at the measurement rig during HT 6, and why the hindcast period is longer for this tide.

During HT 5 swell type waves were dominant with an offshore significant wave height of $0.82 \mathrm{~m}$ and a peak period of $11.3 \mathrm{~s}$. HT 6 is characterized by relatively steep (wind) waves with an offshore significant wave height of $1.5 \mathrm{~m}$ and a peak period of $4.7 \mathrm{~s}$ (Table 2 ).

The grain characteristics at the beach of Truc Vert were also measured during the experiment and are described by Gallagher et al. (2011). A large spatial and temporal variation in grain size (0.2 to $0.7 \mathrm{~mm}$ ) is observed throughout the measurement campaign.

\begin{tabular}{|l|l|}
\hline \multicolumn{2}{|l|}{ Table 2. Characteristics modeling cases Le Truc Vert. } \\
\hline High tide 5 & High tide 6 \\
\hline swell, low waves & sea, medium waves \\
$H_{s, o}=0.82 \mathrm{~m}$ & $H_{s, o}=1.5 \mathrm{~m}$ \\
$T_{p, o}=11.3 \mathrm{~s}$ & $T_{p, o}=4.7 \mathrm{~s}$ \\
accretive & erosive \\
\hline
\end{tabular}

\section{Model setup}

The model domain is located between $\mathrm{x}=-80 \mathrm{~m}$ and $\mathrm{x}=-30 \mathrm{~m}$ (see Figure 1), and the model uses an equidistant grid with a grid spacing of $0.5 \mathrm{~m}$. The initial profile in the model is obtained from the total station beach profile measurements described above. For both simulations the profile measured during the previous low tide is used. Note that the simulation only starts when the water level is high enough to reach the offshore located PT/ADV, and therefore the initial simulation profile might differ (slightly) from the actual beach profile (e.g. due to aeolian transport).

At the offshore boundary the measured water level (from the PT) and velocity (ADV) signal are decomposed into a wave related and a tide related water level time series. The tidal water level variation is simulated as a gradual increase of the mean water level over time, while the wave signal is further decomposed into an incoming and outgoing (reflective) water level time series according to Guza et al. (1984). The incoming wave signal is then applied as an instantaneous (4 Hz) water level signal at the offshore model boundary.

Lastly, the characteristic grain size is defined in the model, with $D_{50}=0.3 \mathrm{~mm}$ and $D_{90}=0.45 \mathrm{~mm}$, which seems acceptable according to the measurements (Gallagher et al., 2011). 


\section{MODEL RESULTS}

\section{Hydrodynamics}

First the hydrodynamics are considered. In Figure 1 the measurement locations are shown that are used to verify the modeled hydrodynamics. In addition to the location at the offshore boundary (indicated by the square), four measurement locations in the swash are considered in this study (circles).

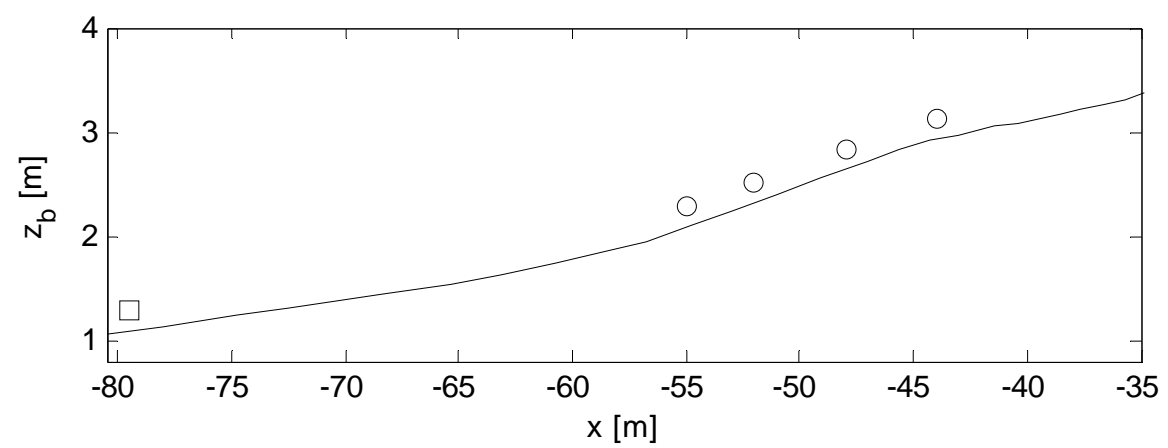

Figure 1. Measurement locations along the coastal bottom profile (and model domain) used for comparison with model output (where the vertical axis represents bed level height and the horizontal axis is the crossshore distance). The square represents the (offshore) PT/ADV, while the circles represent the acoustic bed level sensors in the swash.

Figure 2 (upper panel) shows the measured and computed water surface elevation at the offshore boundary during HT 5 for a 200s time window, which is found to be representative for the entire simulation time. The modeled water level elevation shows good agreement with the measurements, despite some underestimation of the wave troughs in the signal. The computed velocity signal shows a fairly good agreement with the measurements (Figure 2, lower panel). The underestimations of the water surface elevation in the wave troughs can possibly be attributed to the occurrence of some noise in the measured velocity signal, or to the decomposition method used here (which assumes a horizontal bed). Another option could be that the wave transformation in the model deviated from the wave transformation in reality, for instance due to a difference in wave reflection.

For HT 6 the model generally shows the same behavior as for HT 5 with a rather good agreement for the water surface elevation (Figure 3, upper panel) and the velocity (Figure 3, lower panel). Like for HT 5 the troughs are slightly underestimated, whereas in this case the velocity peaks are also somewhat underestimated. The occurrence of noise in the measured velocity time series is very clear (Figure 3, lower panel) and is suggested to be an important contributor to the underestimation of the wave troughs by the model (since the velocity is used in the decomposition of the offshore water level signal into an incoming and outgoing wave signal). Overall, the model seems to be able to reproduce the hydrodynamics at the offshore model boundary rather well. 

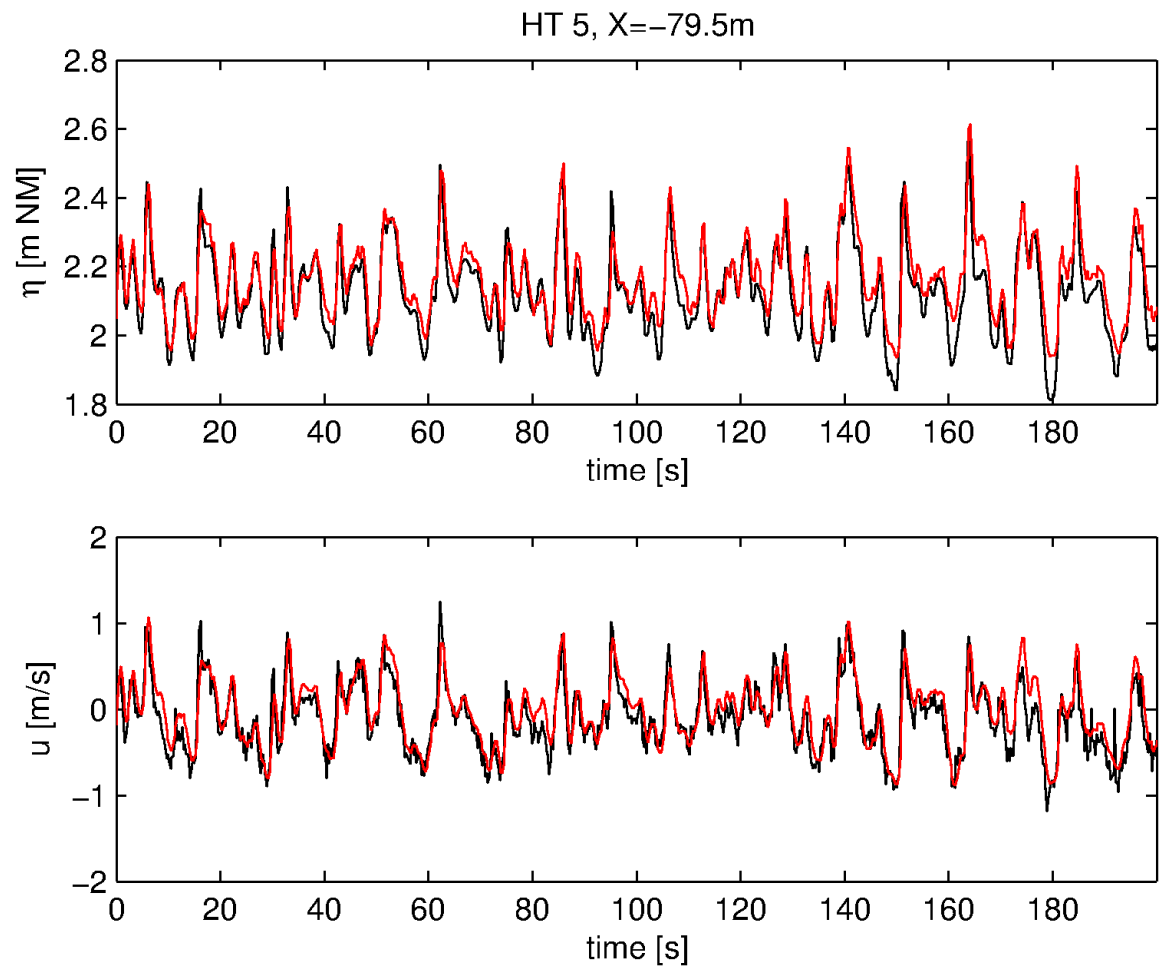

Figure 2. Top panel: comparison between measured (black) and computed (red) water surface elevation (in meter with respect to MSL) at the offshore model boundary $(x=-79.5 \mathrm{~m})$ for a 200 s time window during $\mathrm{HT} 5$. Bottom panel: idem for the velocity.

HT $6, X=-79.5 m$
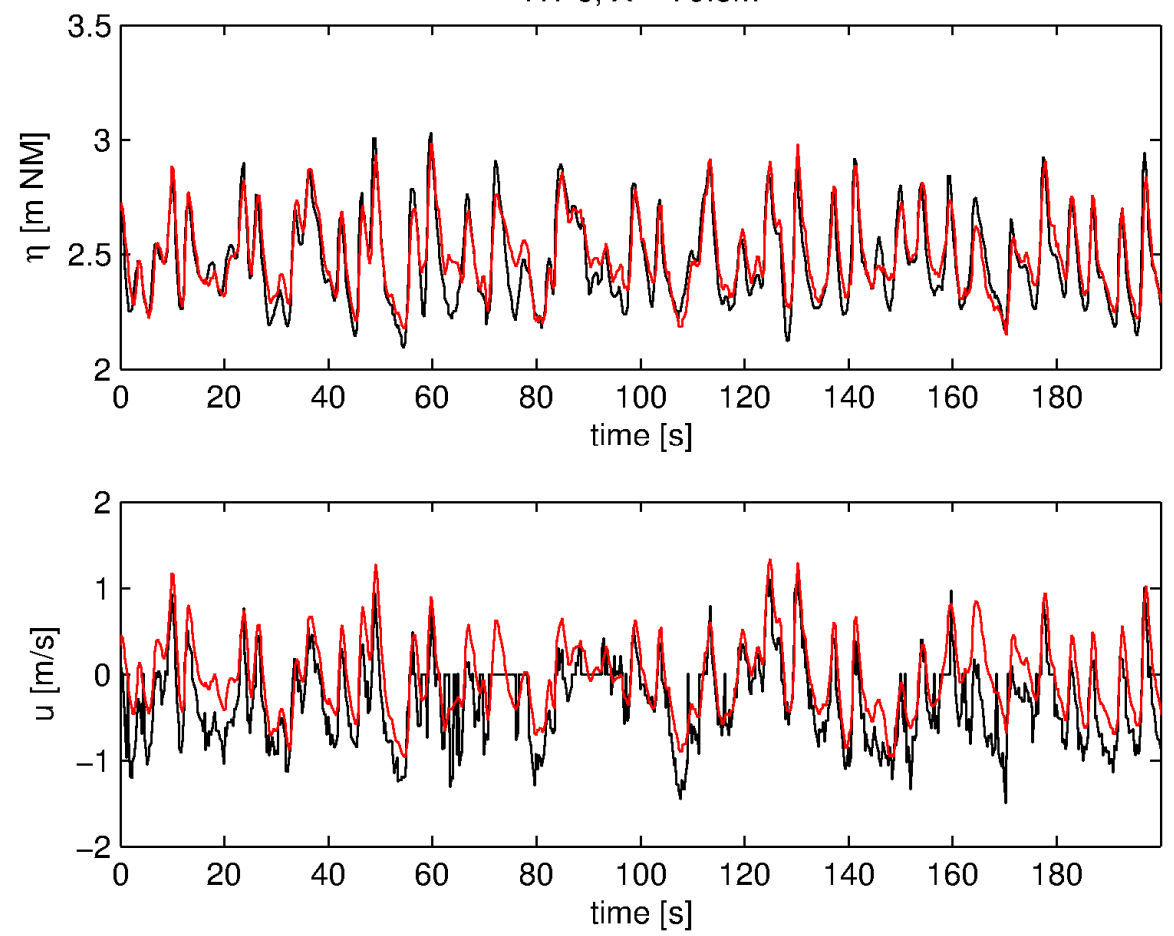

Figure 3. Top panel: comparison between measured (black) and computed (red) water surface elevation (in meter with respect to MSL) at the offshore model boundary $(x=-79.5 \mathrm{~m})$ for a 200 s time window during HT 6 . Bottom panel: idem for the velocity.

In Figure 4 the measured and computed water surface elevation in the model domain are plotted for the four measurement locations in the swash (see circles Figure 1), for the same 200s time window 
during HT 5 as in Figure 2. The upper panel shows that the model results for the most seaward located measurement point $(\mathrm{x}=-55.8 \mathrm{~m})$ give rather good agreement with the measured water level elevations. For the second location $(\mathrm{x}=-51.9 \mathrm{~m})$ it can be observed that the model captures some, but not all swash events. This is even more clear in the third location $(x=-48.1 \mathrm{~m})$ where during the 200 s time window three swash events were observed, but only one was modeled. When looking at other 200s time windows similar results are found; at the offshore boundary the model seems to predict the water levels and velocities rather well, whereas water levels near the coast are underestimated and swash events are regularly not reproduced by the model.

For HT 6 the same results are plotted in Figure 5, showing water level time series (measured and computed) at the four swash measurement locations. In contrast to HT 5, for HT 6 the model is able to simulate the water motion much better within the swash zone, even though the run-up still seems slightly underestimated. The actual water level is sometimes over- or underestimated, but the measured swash events are generally captured in the model, even in the most shoreward located measurement location $(\mathrm{x}=-44.3 \mathrm{~m})$. Again comparable results are found when looking into different 200s time windows throughout the simulation period.

HT $5, X=-55.8 m$
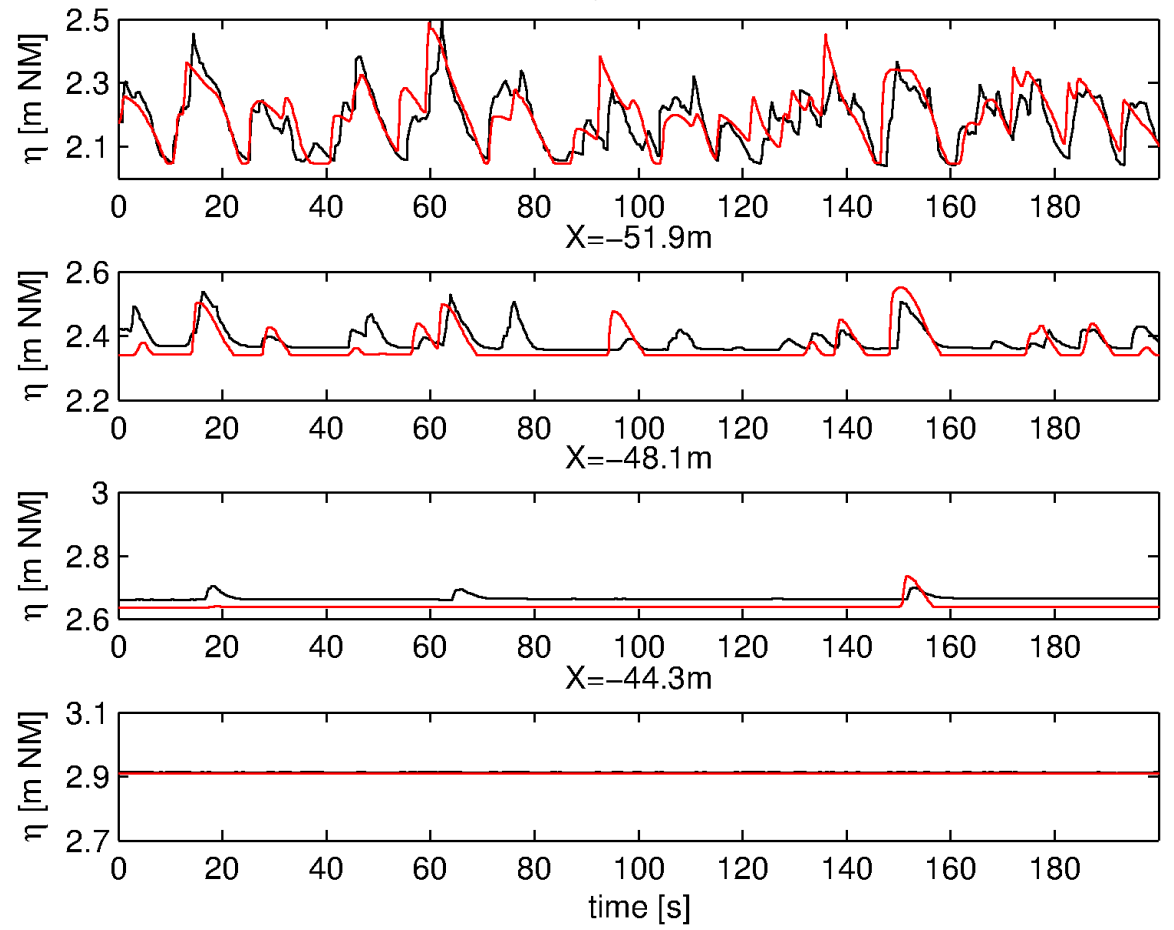

Figure 4. Comparison between measured (black) and computed (red) water surface elevation time series at the four locations in the swash zone during HT 5. 

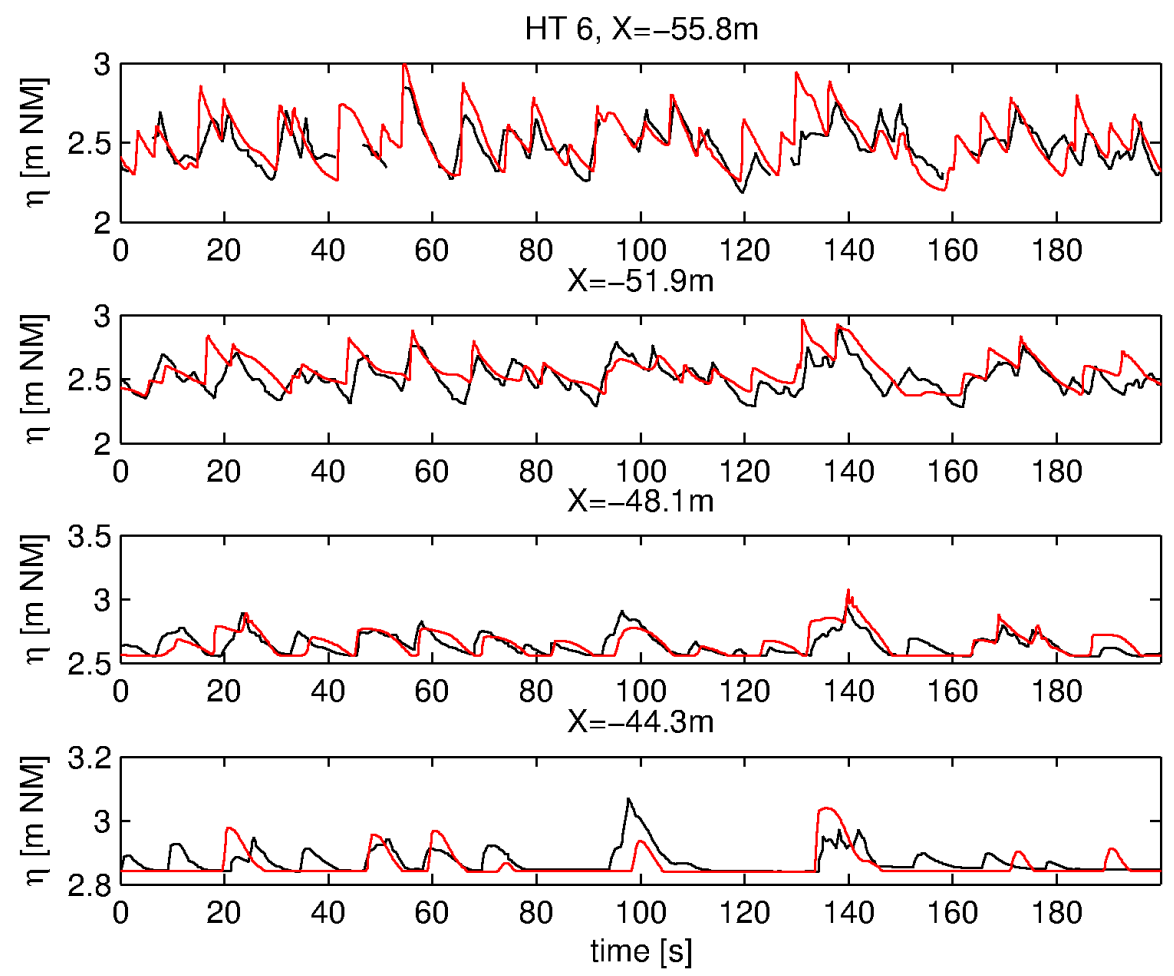

Figure 5. Comparison between measured (black) and computed (red) water surface elevation time series at the four locations in the swash zone during HT 6.

\section{Bed level changes}

During each low tide, the coastal profile was measured with a total station. Based on these measurements the total bed level changes during the (high) tidal cycle are compared with the modeled bed level changes. In Figure 6 the measured and computed bed level changes are plotted for HT 5. The figure shows that the net bed level changes in the swash zone are in the order of $5 \mathrm{~cm}$, and that the net sediment transport direction is onshore directed (accretion). The model results show a similar morphological response and transport direction, however there is a clear spatial shift (of about 8m) with respect to the measurements.

For HT 6 the measured and computed bed level changes are shown in Figure 7, showing a very good agreement. The location, magnitude (about $15 \mathrm{~cm}$ ), as well as the dominant sediment transport direction (offshore directed, or erosion) is well represented by the model. The measurements do show erosion roughly between $\mathrm{x}=-45 \mathrm{~m}$ and $\mathrm{x}=-40 \mathrm{~m}$, whereas this is not represented by the model. However, the model overall provides a satisfying representation of the actual morphological changes that occurred during high tide 6 .

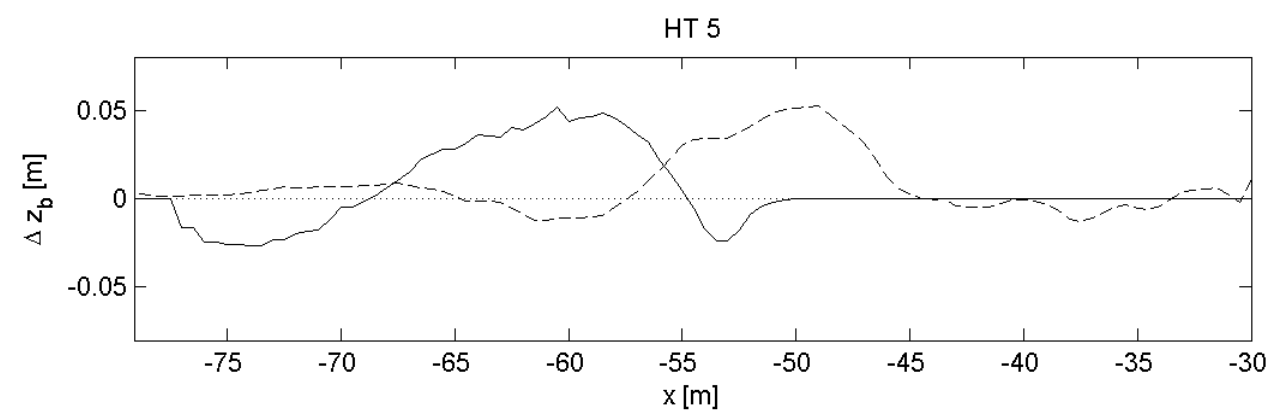

Figure 6. Measured (dashed line) and computed (solid line) total bed level changes along the cross-shore profile during tide 5 , where positive (negative) bed level changes indicate accretion (erosion). 


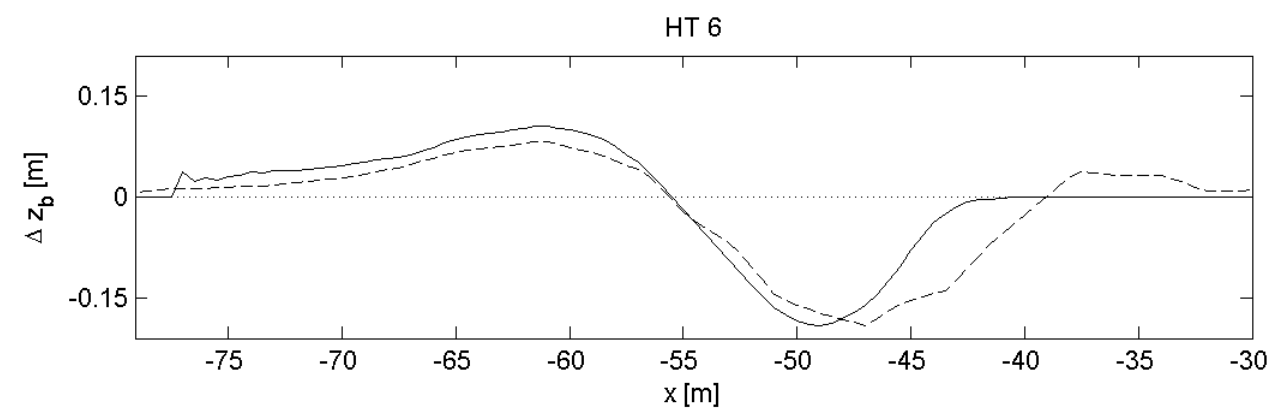

Figure 7. Measured (dashed line) and computed (solid line) total bed level changes along the cross-shore profile during tide 6, where positive (negative) bed level changes indicate accretion (erosion).

To look further into the bed level changes, the combined water level/bed level time series shown in Figure 2 to 5 are shown again in Figure 8, but now for the full simulation period. Note that the difference between the modeled and measured bed level at the end of the simulation is sometimes rather large (for example for HT 6 at location $\mathrm{x}=-55.8 \mathrm{~m}$ ), while in Figure 7 practically no difference between modeled and measured bed level changes is visible. This is a result of the alongshore averaging of the beach profiles measured during each low tide and used to compute the total bed level changes shown in Figure 7. The alongshore averaging leads to a more 1D like situation, which explains why the (1D) model results match the measurements better. The instantaneous bed level measurements shown in Figure 8 are not alongshore averaged.

When comparing the results for HT 5 and HT 6 it can clearly be observed that the water levels are underestimated more for HT 5 than for HT 6 (the measured water surface elevations in black exceed the simulated time series in red). For the most offshore directed swash location $(\mathrm{x}=-55.8 \mathrm{~m})$ this might not be that apparent, but for the other two locations it can clearly be seen that from the start of the simulation, the model underestimates the water levels for HT 5, while for HT 6 the model seems to perform reasonably well. When zooming in on the time series (not shown here), this observation is even more confirmed.

Based on this observation it is concluded that the spatial shift in the morphodynamics (Figure 6) is more likely a result of the erroneous simulated hydrodynamics than of the sediment transport model we want to specifically test here. An evident explanation for underestimating wave run-up might be the overestimation of the bed friction. However, varying the friction parameter in the model did not have any significant effect here. A number of other explanations for the (hydrodynamic) mismatch are suggested, such as for instance 2D effects, or wind setup, which both are not included in the model. However, the model domain is rather small, and researchers did find a strong dominance of cross-shore processes during the measurements. 

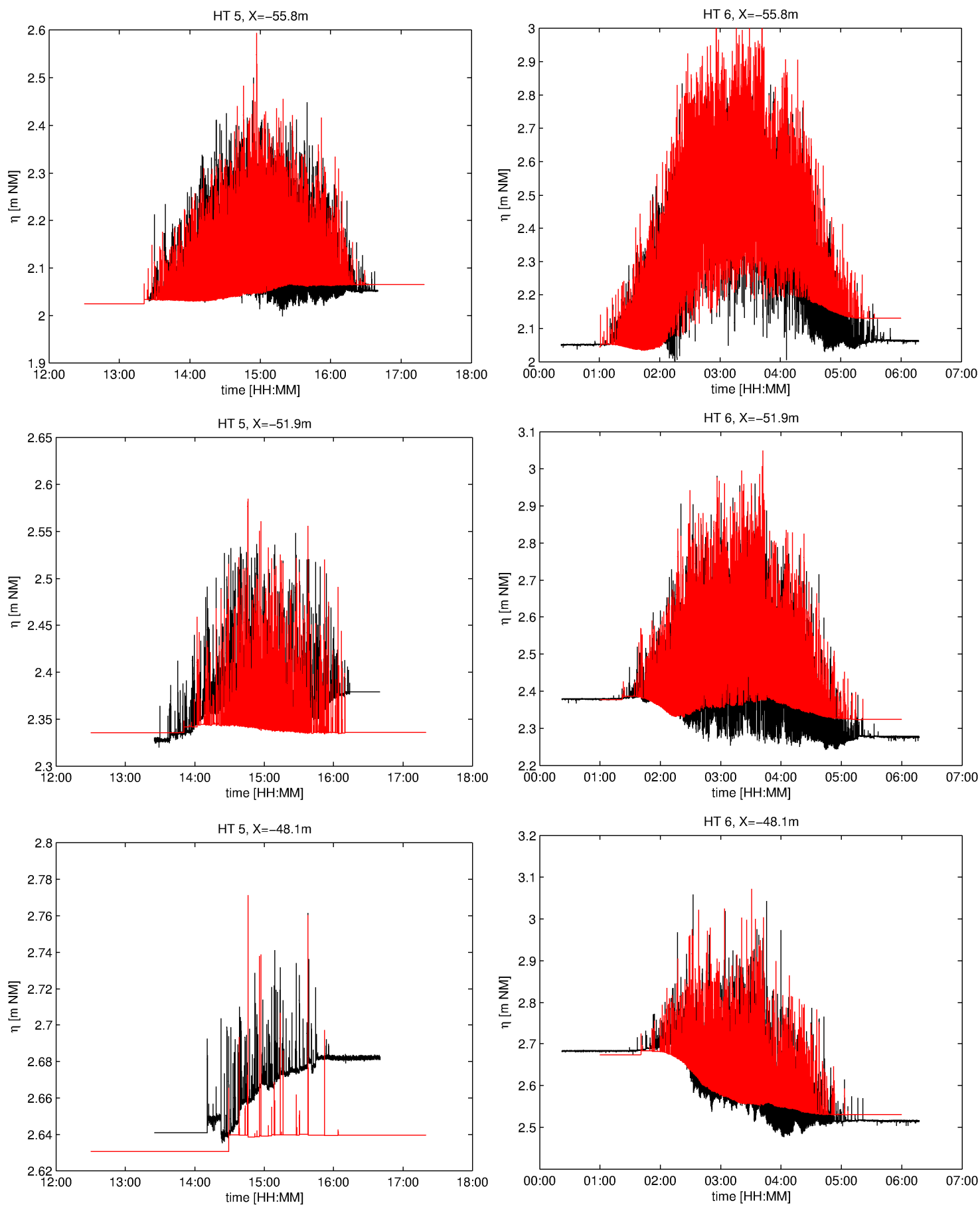

Figure 8. Complete measured (black) and computed (red) water level/bed level time series for three locations (upper, middle and lower panel) for HT 5 (left) and HT 6 (right).

\section{CONCLUSIONS}

A one-dimensional hydrostatic XBeach model has been applied to hindcast morphodynamics in the swash zone during two tidal events, that were measured during a large field campaign at Le Truc Vert beach (France) in early spring 2008. The model solves the hydrodynamics using the nonlinear shallow water equations and is coupled with a combined Nielsen and Bagnold type sediment transport model. The first tide was characterized by swell waves and accretion took place in the swash zone, while during the second tide wind waves were dominant and the swash zone eroded. 
Based on the model-data comparison it is concluded that the model is able to simulate processes on a small scale in the swash zone reasonably well, for both accretive and erosive conditions. The model is able to pick up most of the swash events, although the water level at the shoreline is underpredicted (especially for the accretive tide). This underestimation of the wave setup and/or run-up causes a spatial shift of about 8 meters in seaward direction in the simulated morphological evolution.

The wave and swash motion are solved with the nonlinear shallow water equations, which are expected to be accurate (since the shallow water criterion is fulfilled). It is, therefore, hypothesized that the underprediction of the water level setup or wave run-up can possibly be associated with 2D-effects, which are not taken into account in the present (1D) simulations.

The underestimated wave setup and/or run-up could of course also be a result of an erroneous morphological evolution (where the computed bed level changes affect the local hydrodynamics). However, when compensating for the spatial shift, the total bed level changes were computed satisfactorily (both in magnitude and net transport direction), it is concluded that the 1D hydrostatic model in combination with the Nielsen / Bagnold transport model provides a fairly good representation of the measured morphodynamics, and can be helpful in further understanding the complex processes in the swash zone.

\section{ACKNOWLEDGMENTS}

Arnold van Rooijen was funded by Deltares Coastal Care (Kustlijnzorg) and the MICORE project. Ad Reniers was funded through NSF grant EAR 0952225.

\section{REFERENCES}

Ahrens, J. P. 2000. The fall-velocity equation. Journal of Waterway, Port, Coastal, and Ocean Engineering (126) 99-102.

Bagnold, R. A. 1966. An approach to the sediment transport problem from general physics. Prof. Paper 422-1, United States Geological Survey.

Bakhtyar, R., D.A. Barry, L. Li, D.S. Jeng \& A. Yeganeh-Bakhtiary. 2009. Modeling sediment transport in the swash zone: A review. Ocean Engineering, 36(9-10), 767-783.

Blenkinsopp, C. E., I. L. Turner, G. Masselink \& P. E. Russell. 2011. Swash zone sediment fluxes: Field observations. Coastal Engineering, 58(1), 28-44.

Fredsøe, J., \& R. Deigaard. 1992. Mechanics of coastal sediment transport (Vol. 3): World Scientific.

Galappatti, R. \& C. B. Vreugdenhil, 1985. A depth integrated model for suspended transport. Journal of Hydraulic Research, 23 (4) , 359-377.

Gallagher, E. L., J. MacMahan, A. J. H. M. Reniers, J. Brown \& E. B. Thornton. 2011. Grain size variability on a rip-channeled beach. Marine Geology (287), 43-53.

Guza, R. T., E. B. Thornton, \& R. A. Holman. 1984. Swash on steep and shallow beaches. Paper presented at the 19th Conference on Coastal Engineering, Houston, Texas.

Masselink, G., P. Russell, I. Turner, \& C. Blenkinsopp. 2009. Net sediment transport and morphological change in the swash zone of a high-energy sandy beach from swash event to tidal cycle time scales. Marine Geology, 267(1-2), 18-35.

Meyer-Peter, E., R. Müller. 1948. Formulas for bed-load transport. Proc. 2nd Congress of the Int. Ass Hydraulic Structures Research, Stockholm.

Nielsen, P. 1992. Coastal bottom boundary layers and sediment transport (Vol. 4). Singapore: World Scientific.

Nielsen, P. 2002. Shear stress and sediment transport calculations for swash zone modelling. Coastal Engineering, 45(1), 53-60.

Reniers, A.J.H.M., E.L. Gallagher, J.H. MacMahan, J.A. Brown, A.A. van Rooijen, J.S.M. van Thiel de Vries \& B. van Prooijen, (submitted). Observations and modeling of steep-beach grain-size variability. Journal of Geophysical Research.

Roelvink, J. A., \& M. J. F. Stive, 1989. Bar-Generating Cross-shore Flow Mechanisms on a Beach. Journal of Geophysical Research, 94(No. C4), 4785-4800.

Roelvink, J. A., A. J. H. M. Reniers, A. R. van Dongeren, J. S. M. van Thiel de Vries, R. T. McCall \& J. Lescinski. 2009. Modelling storm impacts on beaches, dunes and barrier islands. Coastal Engineering, 56(11-12), 1133-1152.

Sénéchal, N., F. Ardhuin, \& others 2008. Qualification des modèles de houle et de morphodynamique. Proceedings of the Journées nationales Génie Côtier. 
Shields, A., 1936. Anwendung der Ahnlichkeitsmechanik und Turbulenzforschung auf die Geschiebebewegung. Mitt Preuss Versuchsanstalt fur Wasserbau und Schiffbau, No 26, Berlin.

Soulsby, R. L. 1997. Dynamics of Marine Sands: a manual for practical applications. London: Thomas Telford Publications.

Stockdon, H. F., R. A. Holman, P. A. Howd \& A. H. Sallenger Jr. 2006. Emperical parameterization of setup, swash, and runup. Coastal Engineering, 53(7), 573-588.

Swart, D. H. 1974. Offshore sediment transport and equilibrium beach profiles. Laboratory Publication No. 131, Delft Hydraulics.

van Rijn, L. C. 2007. Unified View of Sediment Transport by Currents and Waves. I: Initiation of Motion, Bed Roughness, and Bed-load Transport. II: Suspended transport. III: Graded beds. Journal of Hydraulic Engineering, 133(6), 649-775. 